\title{
Fabrication of multi-specialty textile surfaces via. In-situ deposition of metal oxide nanoparticles
}

\author{
Priyanka Katiyar*, Shraddha Mishra, M.K. Sinha, Anurag Srivastav and N. Eswara Prasad \\ Defence Materials and Stores Research \& Development Establishment, Kanpur-208013, India \\ *Email: priyanka.drdo@gmail.com
}

Nanotechnology can be effectively used to impart multi-specialty attributes on any textile surface in a single step process [1]. The functional properties, which can be incorporated, are water repellency, oil repellency, flame retardancy, antimicrobial, etc without alerting their inherent properties like handle, durability, breathability, etc. Nanosized particles of titanium oxide $\left(\mathrm{TiO}_{2}\right)$, aluminium oxide $\left(\mathrm{Al}_{2} \mathrm{O}_{3}\right)$, zinc oxide $(\mathrm{ZnO})$, and magnesium oxide $(\mathrm{MgO})$ are a group of metal oxides that possess photocatalytic ability, ultraviolet (UV) absorption and photooxidizing capacity against chemical and biological species $[2,3]$. These properties of the metal oxide nanoparticles can be incorporated onto textile substrate alone or in conjunction. This paper aims to develop textiles surfaces possessing some of the above said properties by synthesis of $\mathrm{TiO}_{2}, \mathrm{SiO}_{2}$ and their hybrid nanosols at low temperature and their in-situ deposition onto textiles surfaces followed by surface modification. SEM analysis depicts an in-situ continuous, well adhered, very fine nanosized coating of nanoparticles via sol-gel route onto inherent flame retardant polyester substrate. Further, stain degradation and dye degradation analysis of coated substrates has been done. Stain degradation test under mild UV irradiation shows almost 80-90\% degradation of stain within 4 hours measured by Spectrophotometer (Figure 1).

UV-Vis Absorption Spectroscopy as depicted in Figure 2 shows complete degradation of Methyl Orange Dye within 3 hours. As prepared nanosol coated long chain alkylalkoxysilane modified textile surfaces are showing apparent water contact angle as $\sim 145^{\circ}$, which is much closed to proximity of superhydrophobic surfaces.

The effect of this treatment on coated substrates is also studied in terms of change in physical properties and no alteration has been observed.

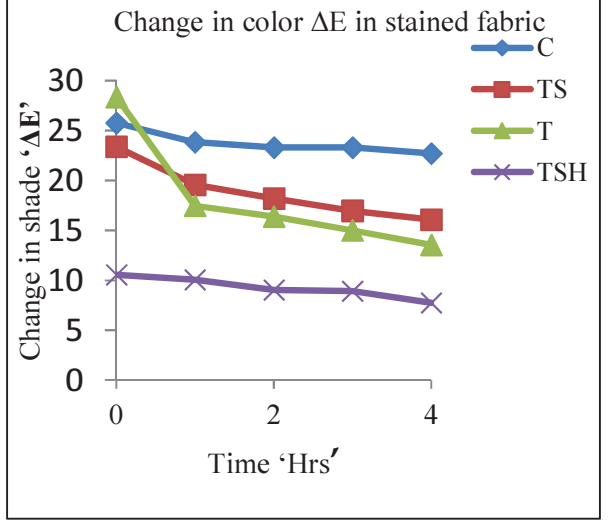

Figure 1: Degradation of stain as a function of UV irradiation time for different substrates: C-original fabric, T-nano $\mathrm{TiO}_{2}$ coated, TS-nano $\mathrm{TiO}_{2}-\mathrm{SiO}_{2}$ coated, TSH- modified nano $\mathrm{TiO}_{2}-\mathrm{SiO}_{2}$ coated fabric

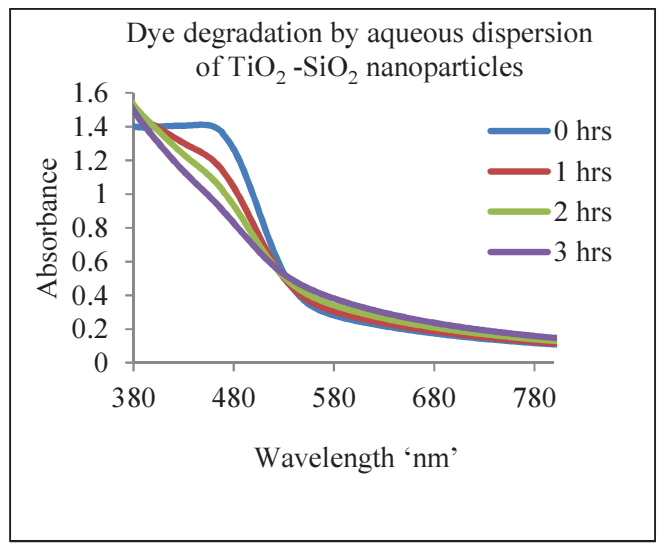

Figure 2: Degradation of Methyl Orange Dye in aqueous dispersion of $\mathrm{TiO}_{2}-\mathrm{SiO}_{2}$ nanoparticles.

\section{References}

1. S. S. Kathiervelu, Synthetic Fibres, 32(2003) 2022.

2. P. J. Brown, K. Stevens, (UK: Woodhead Publishing Limited and CRC Press, 2007).

3. R. Dastjerdi, M. Montazer, S. Shahsavan, Colloids Surf B: Biointerfaces 81(2010) 32-41. 